Published in final edited form as:

J Adolesc Health. 2017 March ; 60(3): 277-283. doi:10.1016/j.jadohealth.2016.10.020.

\title{
Provider Influences on Sperm Banking Outcomes among Adolescent Males Newly Diagnosed with Cancer
}

\author{
James L. Klosky, Ph.D. ${ }^{a}$, L. Elizabeth Anderson, B.A. ${ }^{d}$, Kathryn M. Russell, Ph.D. ${ }^{a}$, Lu \\ Huang, M.S. ${ }^{b}$, Hui Zhang, Ph.D. ${ }^{b}$, Leslie R. Schover, Ph.D. ${ }^{e}$, Jessica L. Simmons, M.S. ${ }^{a}$, and \\ William H. Kutteh, M.D., Ph.D. ${ }^{c, f}$ \\ aSt. Jude Children's Research Hospital, Department of Psychology, 262 Danny Thomas Place, \\ Memphis, TN 38105

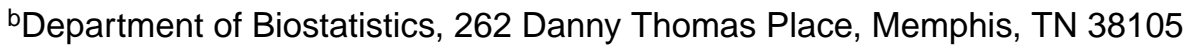 \\ 'Department of Surgery, 262 Danny Thomas Place, Memphis, TN 38105 \\ dUniversity of Tennessee College of Medicine, 910 Madison, Suite 1002, Memphis, TN 38163 \\ eMD Anderson Cancer Center, Department of Behavioral Science, 1155 Pressler Street, Houston, \\ TX 77030
}

${ }^{\mathrm{f} F e r t i l i t y ~ A s s o c i a t e s ~ o f ~ M e m p h i s, ~} 80$ Humphreys Center \#307, Memphis, TN 38120

\begin{abstract}
Purpose-To examine provider communication and sociodemographic factors which associate with sperm banking outcomes in at-risk adolescents newly diagnosed with cancer.
\end{abstract}

\begin{abstract}
Methods-A prospective single group quasi-experimental study design was utilized to test the contributions of provider factors on sperm banking outcomes. Medical providers ( $\mathrm{N}=52,86.5 \%$ oncologists) and 99 of their at-risk adolescent patients from eight leading pediatric oncology centers in North America completed questionnaires querying provider factors and patient sperm banking outcomes. Logistic regression with single covariates was utilized to test each provider factor as a potential correlate of the two binary sperm banking study outcomes (collection attempt/no attempt and successful sperm bank/no bank). Multi-covariate logistic regression was used to calculate odds ratios (OR) and 95\% confidence intervals (CIs) for specified banking outcomes.
\end{abstract}

Results-Fertility referral (OR=9.01, 95\% CI=2.54-31.90, $\mathrm{p}<.001)$ and provider comfort/skills in negotiating barriers to sperm banking with families $(\mathrm{OR}=1.94,95 \% \mathrm{CI}=1.03-3.63, \mathrm{p}<0.04)$ were associated with collection attempts. Adolescents who were referred for a specialized fertility

Corresponding Author: James L. Klosky, PhD, Department of Psychology, St. Jude Children's Research Hospital, 262 Danny Thomas Place, Mail Stop 740, Memphis, Tennessee 38105-2794, Phone: (901)-595-5057, Fax: (901)-595-4701, james.klosky@stjude.org.

Publisher's Disclaimer: This is a PDF file of an unedited manuscript that has been accepted for publication. As a service to our customers we are providing this early version of the manuscript. The manuscript will undergo copyediting, typesetting, and review of the resulting proof before it is published in its final citable form. Please note that during the production process errors may be discovered which could affect the content, and all legal disclaimers that apply to the journal pertain.

Disclosures: Drs. Klosky, Russell, Zhang, Schover and Kutteh and Ms. Anderson, Huang, and Simmons have no potential conflicts of interest, including specific financial interests, relationships or affiliations relevant to the subject of this manuscript. 
consultation were also almost 5 times more likely to successfully bank (OR=4.96, 95\% $\mathrm{CI}=1.54$ $16.00, \mathrm{p}<.01)$ relative to those who were not.

Conclusions-Provider training in communicating/managing adolescents and their families about sperm banking, and increasing utilization of fertility preservation referrals, should increase the proportion of at-risk males preserving fertility prior to treatment initiation.

Title Registration-Clinicaltrials.gov NCT01152268

\section{Keywords}

sperm banking; cryopreservation; fertility preservation; infertility; pediatric cancer; adolescent males

Eighteen in 100,000 children and adolescents are diagnosed with cancer each year in the United States. The majority of these children survive into adulthood, with 5-year survival rates exceeding $80 \% .{ }^{1}$ Given the increased life expectancy of childhood cancer patients, special attention is being placed on controlling the adverse late effects of cancer treatment on quality of life outcomes.

Cancer therapy affects fertility in survivors, ${ }^{2-3}$ and infertility has a negative impact upon survivors' psychological well-being. ${ }^{4-5}$ Due to the seriousness of this issue, the American Society of Clinical Oncology recommends that healthcare providers discuss risk of infertility and options to preserve fertility with all patients of reproductive age prior to cancer therapy. ${ }^{6}$ The gold standard in fertility preservation for males is sperm cryopreservation, a method that has been successfully utilized for the past fifty years. ${ }^{7-8}$ Most adolescent cancer patients who attempt to bank sperm can produce a high quality sample that can later be used in assisted reproductive technologies. ${ }^{9-10}$ Adolescents who engage in fertility preservation report high decisional satisfaction regarding the banking process and outcome. ${ }^{11}$

Despite the benefits of cryopreservation, only a minority of adolescents bank sperm prior to the initiation of cancer therapy. ${ }^{12}$ Several qualitative, retrospective studies have explored barriers to fertility preservation and have suggested that the quality of discussions with healthcare providers regarding risk of infertility affects patient decision making specific to sperm banking. ${ }^{13-15}$ However, to date, no studies have used quantitative designs to explore the extent that providers influence adolescent decision making regarding fertility preservation.

Previous research has found that healthcare providers' recommendations have a significant influence upon adolescent decision-making. Studies considering adolescent receipt of the human papillomavirus vaccination, for example, suggest that a provider's recommendation in favor of the vaccination increases the likelihood of adolescent initiation. ${ }^{16-17}$ As sperm banking is another sensitive healthcare decision that adolescents and their families face, it is possible that providers have a similar effect upon an adolescent's decision to cryopreserve sperm. Further, research focusing on adult cancer patients has found that men whose providers discuss cryopreservation more frequently bank sperm. ${ }^{18}$ It has been hypothesized that provider communication has a similar effect among adolescent patients. ${ }^{19}$ Quantifying provider influence on adolescent sperm banking outcomes is important in developing 
interventions designed to maximize the proportion of adolescent cancer patients who bank sperm. Therefore, the purpose of this study is to examine the influence of provider communication factors as they relate to sperm banking outcomes among adolescent males newly diagnosed with cancer. Provider sociodemographic variables were also explored as well.

\section{Methods}

\section{Participants}

In order to be eligible for the study, medical providers were required to be currently providing care to a patient who was male, newly diagnosed with a first cancer, 13-21 years of age (inclusive), Tanner stage III or higher, proficient in speaking and reading English or Spanish, and possessing the cognitive capacity to complete study questionnaires.

Furthermore, the adolescent patient must have been identified by the attending oncologist (or designee) as being at increased risk for treatment-related infertility secondary to impending cancer treatment. From $2011-2014$, a total of 52 providers across 8 leading pediatric oncology institutions in the US and Canada, caring for 99 patients meeting the above eligibility criteria, agreed to participate in the current study. These providers consisted of 45 oncologists, 5 nurse practitioners, and 2 social workers.

\section{Design and Method}

A single group quasi-experimental study design was utilized to test the role of provider communication and sociodemographic factors as they relate to the specified sperm banking study outcomes. Prior to study enrollment, study team members systematically completed daily eligibility checklists for all potentially eligible adolescent patients at their respective institutions. Once the medical record review was completed and initial study criteria was met for a new patient, the adolescent's oncologist was emailed and queried regarding the fertility risk status of the adolescent patient in question (fertility risk score ranging 0 no risk to 3 high risk). Only after the oncologist rated the participant as being at increased risk for infertility (e.g. risk score 21 ) was the patient considered eligible for the study. Once a patient enrolled, the provider was sent a link to complete a very brief on-line provider questionnaire querying whether they had a discussion with the adolescent/family regarding the participant's risk for treatment-related infertility. The provider was also queried as to whether or not sperm banking was recommended to the adolescent. For those providers who were completing the provider questionnaire for the first time, they were asked to provide additional information regarding their sociodemographic information, while rating their general communications and comfort in discussing patient fertility risk and the demands/ process of banking sperm (see example of items in Tables 2 and 3).

Eligible adolescents were also approached between Day 1 and Day 7 post initiation of cancer treatment for study enrollment (between Day 2 and 15 for the Canadian site). Those families who agreed to participate signed consent/assent forms following an explanation of this institutional review board (IRB)-approved study. Adolescents completed a questionnaire that assessed, in part, perceptions of their provider's behavior related to sperm banking discussion. 
Adolescents and providers were asked whether someone other than the primary oncologist on the medical team (e.g., nurse or social worker) may have had discussions with the family about risk of infertility or banking sperm and those staff were sent the provider questionnaires as well. The provider questionnaire took approximately 5 minutes to complete whereas the adolescent questionnaire took approximately 20 minutes. All adolescents were provided with a $\$ 12.50$ gift card upon completion of the questionnaires as an incentive for study participation and compensation for their time. Compensation was not provided to the providers.

\section{Independent Variables}

Adolescents and providers completed a brief seven item scale regarding the provider's communication style when discussing features of sperm banking with the adolescent, including (a) comfort in discussing treatment effects on fertility, (b) comfort discussing the process of banking, (c) confidence in predicting treatment effects on fertility, (d) knowledge about treatment effect's on fertility, (e) provision of a recommendation for/against banking, (f) delivery of that message with conviction, and (g) discussing the pros and cons of banking. Providers completed an additional five items, which were all adapted from previously published literature. ${ }^{18,20-22}$ These additional items were (a) comfort discussing treatment effects on fertility with parents and with patients (separate questions), (b) comfort discussing the process of banking with parents and with patients(separate questions), (c) whether fertility preservation is a priority when working with newly diagnosed males, (d) whether as a matter of practice, they discuss the effect of treatment on future fertility, and (e) comfort negotiating with families who identify barriers to banking. Responses ranged from 1 (Strongly Disagree) to 5 (Strongly Agree).

Sociodemographic information for providers included gender, age (categorical in 10 year increments ranging from 20-29 to 80-89), number of years working with adolescent patients, race (reduced to white/non-white for analyses), and whether they personally had children. See Table 1 for provider sociodemographics.

\section{Primary Outcomes}

The two primary outcomes included (a) collection attempt and (b) successful completion of sperm banking. The collection attempt outcome is a binary (yes/no) variable which was obtained from the adolescent questionnaires. A positive sperm banking attempt was considered when an adolescent participant responded in one of three ways to the item "Have you banked your sperm?" In order to be coded as having made a sperm banking attempt, the participant must have responded "Yes," "No, I tried to but wasn't able to provide a sample" or "No, I provided a sample but there was no sperm in it to bank." Only participants who responded "Yes" to the item "Have you banked your sperm?" were coded as sperm bankers; all others were coded as non-bankers. If this primary outcome variable was missing on the adolescent questionnaire, the corresponding response from the patient's parent questionnaire (collected as part of a larger study, but not otherwise assessed in the current study) was used. As there was $100 \%$ agreement across available adolescent and parent-reports, the validity of the banking report is considered robust. 


\section{Statistical Approach}

To build the regression model with the most appropriate variables selected as covariates, a three-step statistical plan was employed which incorporated conventional univariable selection based on a priori standards, the Bayesian information criteria (BIC), and best subsets regression. This study choose BIC, as it is one of the most widely used criterions for model selection among a finite set of one of the most widely used criterions for model selection among a finite set of covariate combinations in multivariate analysis. While adding covariates increases the likelihood, it may also result in overfitting. However, BIC resolves this by using a penalty term. ${ }^{23}$ Compared with its major competitor Akaike information criterion (AIC), ${ }^{24}$ the penalty term in BIC is larger.

For this study, variables under consideration came from two different sources: adolescents and providers. First, univariate logistic regressions were utilized to examine the contribution of each potential covariate alone to the two binary study outcomes (collection attempt/no attempt and sperm bank/no bank). In the second step, factors with significance $(\mathrm{p}<.10)$ at stage 1 were grouped by source and factor type into a series of three testing logistic regressions: two adolescent-report logistic regressions of (a) provider fertility risk communications and (b) provider comfort during sperm banking discussion, and one provider-report logistic regression of (c) fertility risk communications, which included one provider comfort item. In the final step, covariates which were selected by BIC within each group's logistic regression $(\mathrm{p}<.05)$ were then tested in the final collection attempt and sperm banking models. The results of all logistic regressions are presented in odds ratios (OR) and 95\% confidence intervals (CIs) for the specified banking outcomes.

\section{Results}

Sample

Fifty-two medical providers and 99 adolescents completed questionnaires regarding provider characteristics affecting sperm banking outcomes. Over half of the providers reported on one patient $(\mathrm{n}=30 ; 57.6 \%)$, whereas $23.1 \%$ reported on two patients $(\mathrm{n}=12)$, and another $19.23 \%$ reported on three or more patients $(\mathrm{n}=10)$. Forty-seven adolescents $(47.5 \%)$ made collection attempts and 38 (38.4\%) successfully banked. Providers had varying amounts of clinical experience caring for adolescents (Mean years $=13.0, S D=9.2$ ). Provider genders were equally distributed (males: $\mathrm{n}=25,48.8 \%$; females: $\mathrm{n}=26,50.0 \%$; missing $\mathrm{n}=1$ ), and most of the providers had children $(\mathrm{n}=37,71.2 \%)$. In terms of cancer diagnosis, adolescent patients had leukemia or lymphoma (58.6\%), solid tumors (34.3\%), or brain tumors $(7.1 \%)$. Over half $(n=57,57.6 \%)$ of evaluated adolescents were Tanner Stage 5 (Table 1).

It is important to note that a paired samples t-test revealed that there was no significant difference between provider comfort $(\mathrm{M}=4.64, \mathrm{SD}=0.60)$ and adolescent's rating of provider comfort $(\mathrm{M}=4.54, \mathrm{SD}=.68) ; \mathrm{t}(49)=.87, \mathrm{p}=.39$.

\section{Collection Attempt}

Univariate analyses revealed multiple associations between provider variables and adolescent collection attempts (Tables 2 and 3 ). 
Using the BIC for variable selection, variables were identified for the final logistic regression model for collection attempt. These variables included (a) adolescent report of the following: medical team recommendation of sperm banking, provider communication of fertility risk, provider estimate of fertility risk, medical cues to action, and appointment with a fertility specialist; (b) provider report of the following: adolescent fertility risk, communication of fertility risk with parents and adolescents, referral to a fertility specialist, and comfort negotiating barriers to banking; and (c) adolescent perception of providers' comfort, confidence, and knowledge in the discussion of treatment effect on fertility, discussing advantages and disadvantages of banking, and directly recommending for or against banking.

The final multivariate logistic regression model found the likelihood of making a collection attempt was nine times greater among adolescents who attended a specialized fertility preservation consultation relative to those without this encounter (OR $=9.01,95 \%$ CI: 2.54 $31.90, \mathrm{p}<.001)$. See Table 4. Furthermore, providers who rated themselves as being more comfortable in their skills to negotiate barriers to sperm banking with families had patients who were two times more likely to engage in a sperm banking attempt compared to providers rating themselves as less comfortable in their skills during these negotiations (OR $=1.95,95 \%$ CI: $1.03-3.63, \mathrm{p}<.04)$.

\section{Sperm Banking Completion}

Univariate analyses revealed multiple associations between provider variables and adolescent sperm banking (Tables 2 and 3).

Using the BIC for variable selection, the same variables listed above for the banking model were identified for the final multivariate logistic regression attempt model. In the final banking model, adolescents who completed a specialized fertility preservation consultation were nearly five times more likely to bank sperm relative to those without this referral (OR = 4.96, 95\% CI: 1.52-16.00, p<.01) (Table 5).

\section{Discussion}

When adolescents are diagnosed with cancer, urgency exists for initiating treatment and working toward cure. Provider communication, including recommendation for/against sperm banking, has been reported as a robust predictor of banking outcome. ${ }^{13}$ Due to providers' influential role, more specificity regarding provider communications influencing adolescents' decision-making for fertility preservation are needed. ${ }^{13}, 15$ The present study examined this, and sociodemographic factors, in association with sperm banking outcomes among adolescent males newly diagnosed with cancer.

Being referred for a specialized fertility preservation consultation continues to be the most robust factor associated with making a collection attempt with referred adolescents being over nine times more likely to bank. Providers who perceive themselves as being more comfortable communicating and negotiating with families who identify barriers to sperm banking were also more likely to have patients who make a collection attempt. This finding highlights the importance of providers taking time to discuss fertility preservation with their 
adolescent patients and in assessing, understanding and considering the barriers that families may present. For example, providers who can gently challenge and correct misperceptions that adolescents or their parents may have about banking or future sample utilization (or are knowledgeable about institutional resources which can ameliorate more concrete barriers) appear to be more successful in having patients make a collection attempt. ${ }^{25}$ Although previous research has demonstrated that non-white providers experience greater comfort when discussing sperm banking compared to white providers, ${ }^{26}$ this is a non-modifiable finding and the development of provider negotiation skills is something that can be taught, and improved upon, with intervention.

Similar results were identified in the banking completion model. Specifically, adolescents who were referred for a specialized fertility consultation were almost five times more likely to bank sperm relative to those without this referral. In the pediatric context, these fertility referrals are often made to specialized internal multidisciplinary hospital teams who (when appropriate) then coordinate care with the outside banking facility. It's important to note that there is significant heterogeneity across sites regarding the professional(s) providing these consultations (reproductive endocrinologist, urologist, advanced practice nurse, psychologist) and the content covered in these consultations (risk of infertility secondary to cancer therapy, assessment of sperm banking candidacy, communication of collection expectations/procedural demands, etc.) Regardless, our findings suggest that by referring patients to a specialized fertility team, the likelihood of sperm banking increases. Furthermore, this finding highlights that when existing systems are in place to promote/ reduce barriers to fertility consultations at the time of diagnosis (e.g. existing relationships with specialty providers, willingness of fertility team to "work in" patients for consults with short notice, etc.), at-risk adolescents are more likely to bank. Systems-level interventions designed to standardize and reduce barriers to fertility consultation and sperm banking have been demonstrated to increase fertility preservation among adolescents with cancer, ${ }^{27}$ and as is observed in the collection attempt model, providers who are comfortable/confident in their skills to negotiate and address barriers to banking are particularly influential.

With regard to study limitations, it is possible that an over sampling of oncologists occurred, which may underestimate the influence that other medical professionals (e.g. nurse practitioners, social workers, psychologists, etc.) have on sperm banking practices. Furthermore, parental perceptions of provider comfort and effective communication may also directly affect parental recommendations and, ultimately, the sperm banking outcomes of their sons. However, this report only considers provider and adolescent reports. Finally, there were several important provider factors which differentiated attempters/non-attempters and bankers/non-bankers on the univariate level including provider and medical team recommendation to bank, fertility risk communication by provider to patient and parents, etc. It is not that these variables are unimportant, but rather, our study may be under-powered to reveal these associations in the context of a multivariable analysis. Future, larger studies should consider the influence that these variables may have in sperm banking outcomes among this at-risk group. Another limitation worth noting is that this study only focused on male fertility preservation outcomes and did not include female adolescents newly diagnosed with cancer. Female reproductive health among childhood cancer patients is also in need of further attention and exploration. Comfort will vary between providers discussing fertility 
preservation among young males versus young females due to the different demands of the fertility preservation procedures. While discussions and procedures for male patients are more sexual in nature (e.g. masturbation), discussion for females more has to do with the invasive nature of preparing for and completing egg retrieval (i.e., transvaginal ultrasounds and surgery). Therefore, the comfort levels between providers with female versus male patients may differ and research to determine these differences is clearly warranted.

To highlight the strengths of this study, it is the first to quantify the influence that providers have on collection attempts and successful sperm bankings among at-risk adolescent males newly diagnosed with cancer. The findings of this study highlight the importance of providers making fertility preservation referrals to adolescents as a vehicle to increase collection attempts, and ultimately, the banking of sperm. This finding has not previously been reported in the adolescent cancer literature. Furthermore, the importance of provider skill and comfort in negotiating with adolescents and their families specific to the family's barriers to banking directly associates with collection attempt outcomes. The finding adds to the literature in that physicians who are uncomfortable in discussing sperm banking with adolescent patients have patients who are less likely to make a collection attempt. As such, physicians and other medical professionals who are uncomfortable discussing these topics may need additional training as a mechanism for increasing sperm banking outcomes.

These findings highlight the importance of making fertility preservation referrals to adolescents newly diagnosed with cancer as a vehicle to increase collection attempts, and ultimately, the banking of sperm. The importance of provider skill in negotiating with adolescents on the possibility of making a collection attempt is also noted, particularly among those who note barriers to this process. Fertility preservation is optional and will not be pursued by all patients. By having system-level mechanisms in place for specialized fertility preservation consultation, and providers skilled at negotiating and address barriers to banking attempts, we will have achieved the overall goals of respectfully engaging the adolescent in his own reproductive health decision-making and adhering to the ACSO guidelines, while promoting opportunities for sperm banking among interested patients and families.

\section{Acknowledgments}

Funding: Supported in part by the National Institute of Child Health and Human Development grant no. HD061296 (J. Klosky, Principal Investigator) and United States Public Health Service grant no. CA-21765 (S. Baker, Principal Investigator) with additional support provided to St. Jude Children's Research Hospital by the American Lebanese Syrian Associated Charities (ALSAC).

\section{References}

1. Surveillance, Epidemiology, and End Results (SEER), Cancer Statistics Review 1975-2012. http:// seer.cancer.gov/

2. Thomson AB, Campbell AJ, Irvine DC, et al. Semen quality and spermatozoal DNA integrity in survivors of childhood cancer: a case-control study. Lancet. 2002 Aug 3; 360(9330):361-7. [PubMed: 12241775]

3. Wallace WH, Anderson RA, Irvine DS. Fertility preservation for young patients with cancer: who is at risk and what can be offered? Lancet Oncol. 2005 Apr; 6(4):209-18. [PubMed: 15811616] 
4. Schover LR, Rybicki LA, Martin BA, et al. Having children after cancer. A pilot survey of survivors' attitudes and experiences. Cancer. 1999; 86(4):697-709. [PubMed: 10440699]

5. Nilsson J, Jervaeus A, Lampic C, et al. 'Will I be able to have a baby?' Results from online focus group discussions with childhood cancer survivors in Sweden. Hum Reprod. 2014 Dec; 29(12): 2704-11. DOI: 10.1093/humrep/deu280 [PubMed: 25344069]

6. Loren AW, Mangu PB, Beck LN, et al. Fertility preservation for patients with cancer: American Society of Clinical Oncology clinical practice guideline update. J Clin Oncol. 2013 Jul 1; 31(19): 2500-10. DOI: 10.1200/JCO.2013.49.2678 [PubMed: 23715580]

7. Hourvitz A, Goldschlag DE, Davis OK, et al. Intracytoplasmic sperm injection (ICSI) using cryopreserved sperm from men with malignant neoplasm yields high pregnancy rates. Fertil Steril. 2008 Sep; 90(3):557-63. DOI: 10.1016/j.fertnstert.2007.03.002 [PubMed: 18692822]

8. Daudin M, Rives N, Walschaerts M, et al. Sperm cryopreservation in adolescents and young adults with cancer: results of the French national sperm banking network (CECOS). Fertil Steril. 2015 Feb; 103(2):478-86.e1. DOI: 10.1016/j.fertnstert.2014.11.012 [PubMed: 25527232]

9. Edge B, Holmes D, Makin G. Sperm banking in adolescent cancer patients. Arch Dis Child. 2006 Feb; 91(2):149-152. [PubMed: 16174641]

10. Bahadur G, Ling KL, Hart R, et al. Semen quality and cryopreservation in adolescent cancer patients. Hum Reprod. 2002 Dec; 17(12):3157-61. [PubMed: 12456617]

11. Ginsberg JP, Ogle SK, Tuchman LK, et al. Sperm banking for adolescent and young adult cancer patients: sperm quality, patient, and parent perspectives. Pediatr Blood Cancer. 2008 Mar; 50(3): 594-8. [PubMed: 17514733]

12. Klosky JL, Randolph ME, Navid F, et al. Sperm cryopreservation practices among adolescent cancer patients at risk for infertility. Pediatr Hematol Oncol. 2009 Jun; 26(4):252-60. DOI: 10.1080/08880010902901294 [PubMed: 19437327]

13. Achille MA, Rosberger Z, Robitaille R, et al. Facilitators and obstacles to sperm banking in young men receiving gonadotoxic chemotherapy for cancer: the perspective of survivors and health care professionals. Hum Reprod. 2006 Dec; 21(12):3206-16. [PubMed: 16887922]

14. Green D, Galvin H, Horne B. The psycho-social impact of infertility on young male cancer survivors: a qualitative investigation. Psychooncology. 2003 Mar; 12(2):141-52. [PubMed: 12619146]

15. Chapple A, Salinas M, Ziebland S, McPherson A, MacFarlane A. Fertility issues: the perceptions and experiences of young men recently diagnosed and treated for cancer. J Adolesc Health. 2007 Jan; 40(1):69-75. [PubMed: 17185208]

16. Caskey R, Lindau ST, Alexander GC. Knowledge and early adoption of the HPV vaccine among girls and young women: results of a national survey. J Adolesc Health. 2009 Nov; 45(5):453-62. DOI: 10.1016/j.jadohealth.2009.04.021 [PubMed: 19837351]

17. Rambout L, Tashkandi M, Hopkins L, et al. Self-reported barriers and facilitators to preventive human papillomavirus vaccination among adolescent girls and young women: a systematic review. Prev Med. 2014 Jan.58:22-32. DOI: 10.1016/j.ypmed.2013.10.009 [PubMed: 24176938]

18. Schover LR, Brey K, Lichtin A, et al. Knowledge and experience regarding cancer, infertility, and sperm banking in younger male survivors. J Clin Oncol. 2002 Apr 1; 20(7):1880-9. [PubMed: 11919248]

19. Hobbie WL, Ogle SK, Ginsberg JP. Fertility concerns for young males undergoing cancer therapy. Semin Oncol Nurs. 2009 Nov; 25(4):245-50. DOI: 10.1016/j.soncn.2009.08.001 [PubMed: 19879430]

20. Quinn GP, Vadaparampil ST, Lee JH, et al. Physician referral for fertility preservation in oncology patients: a national study of practice behaviors. J Clin Oncol. 2009 Dec 10; 27(35):5952-5957. [PubMed: 19826115]

21. Quinn G, Vadaparampil ST, Jacobsen P, et al. National survey of physicians practice patterns: fertility preservation and cancer patients. J Clin Oncol. 2009; 27:18s. (suppl; abstr CRA9508).

22. Quinn GP, Vadaparampil ST, King L, et al. Impact of physicians' personal discomfort and patient prognosis on discussion of fertility preservation with young cancer patients. Patient Educ Couns. 2009 Dec; 77(3):338-43. [PubMed: 19796912] 
23. Schwartz G. Estimating the dimension of a model. Ann Statist. 1978; 6(2):461-4. DOI: 10.1214/aos/1176344136

24. Akaike H. A new look at the statistical model identification. IEEE Trans Autom Control. 1974; 19(6):716-23. DOI: 10.1109/TAC.1974.1100705

25. Nahata L1, Cohen LE, Yu RN. Barriers to fertility preservation in male adolescents with cancer: it's time for a multidisciplinary approach that includes urologists. Urology. 2012 Jun; 79(6):1206-9. DOI: 10.1016/j.urology.2012.02.035 [PubMed: 22542423]

26. Klosky JL, Canavera CE, Russell KM, et al. Provider Comfort in Discussing Fertility among Adolescent Males Newly Diagnosed with Cancer. Pediatr Blood Cancer. 2013 Sep.60(S3):177.doi: $10.1002 / \mathrm{pbc}$

27. Shnorhavorian M, Kroon L, Jeffries H, et al. Creating a standardized process to offer the standard of care: continuous process improvement methodology is associated with increased rates of sperm cryopreservation among adolescent and young adult males with cancer. J Pediatr Hematol Oncol. 2012 Nov; 34(8):e315-9. DOI: 10.1097/MPH.0b013e3182678e3a [PubMed: 22983421] 


\section{Implications and Contributions}

Adolescent males newly diagnosed with cancer have increased odds of banking sperm if their providers refer them to a fertility specialist and/or are comfortable/skilled in negotiating perceived barriers to fertility preservation. Provider training to promote these features of care is important to maximize fertility preservation potential. 


\section{Table 1}

Demographic and personal characteristics of provider and adolescent participants ${ }^{a}$

\begin{tabular}{|c|c|c|}
\hline & $\mathbf{n}$ & $\%$ \\
\hline \multicolumn{3}{|l|}{ Providers (N=52) } \\
\hline \multicolumn{3}{|l|}{ Profession } \\
\hline Attending Oncologist & 44 & 84.6 \\
\hline Nurse Practitioner & 5 & 9.6 \\
\hline Social Worker & 2 & 3.8 \\
\hline Fellow & 1 & 1.9 \\
\hline \multicolumn{3}{|c|}{ Experience Caring for Adolescents } \\
\hline $1-5$ years & 13 & 25.0 \\
\hline $6-10$ years & 13 & 25.0 \\
\hline $11-20$ years & 15 & 28.8 \\
\hline $21+$ years & 10 & 19.2 \\
\hline \multicolumn{3}{|l|}{ Age } \\
\hline $20-29$ & 2 & 3.8 \\
\hline $30-49$ & 33 & 63.5 \\
\hline $50-69$ & 16 & 30.8 \\
\hline \multicolumn{3}{|l|}{ Gender } \\
\hline Male & 25 & 48.1 \\
\hline Female & 26 & 50.0 \\
\hline \multicolumn{3}{|l|}{ Race/Ethnicity } \\
\hline White & 35 & 67.3 \\
\hline Non-White & 16 & 30.8 \\
\hline \multicolumn{3}{|l|}{ Have Children } \\
\hline No & 14 & 26.8 \\
\hline Yes & 37 & 70.0 \\
\hline \multicolumn{3}{|l|}{ Adolescents (N=99) } \\
\hline \multicolumn{3}{|l|}{ Diagnosis } \\
\hline Leukemia/Lymphoma & 58 & 58.6 \\
\hline Brain Tumors & 7 & 7.1 \\
\hline Solid Tumors & 34 & 34.3 \\
\hline \multicolumn{3}{|l|}{ Age } \\
\hline $13-15$ & 37 & 37.4 \\
\hline $16-17$ & 30 & 30.3 \\
\hline $18-21$ & 32 & 32.3 \\
\hline \multicolumn{3}{|l|}{ Tanner Stage } \\
\hline Stage 3 & 7 & 7.1 \\
\hline Stage 4 & 33 & 33.3 \\
\hline Stage 5 & 57 & 57.6 \\
\hline \multicolumn{3}{|l|}{ Race/Ethnicity } \\
\hline White & 67 & 67.7 \\
\hline
\end{tabular}




\begin{tabular}{ccc}
\hline & $\mathbf{n}$ & $\boldsymbol{\%}$ \\
\hline Non-White & 32 & 32.3 \\
\hline
\end{tabular}

${ }^{a}$ Values may not equal 52 (Providers) or 99 (Adolescents) due to missing data 


\section{록 \\ 골}

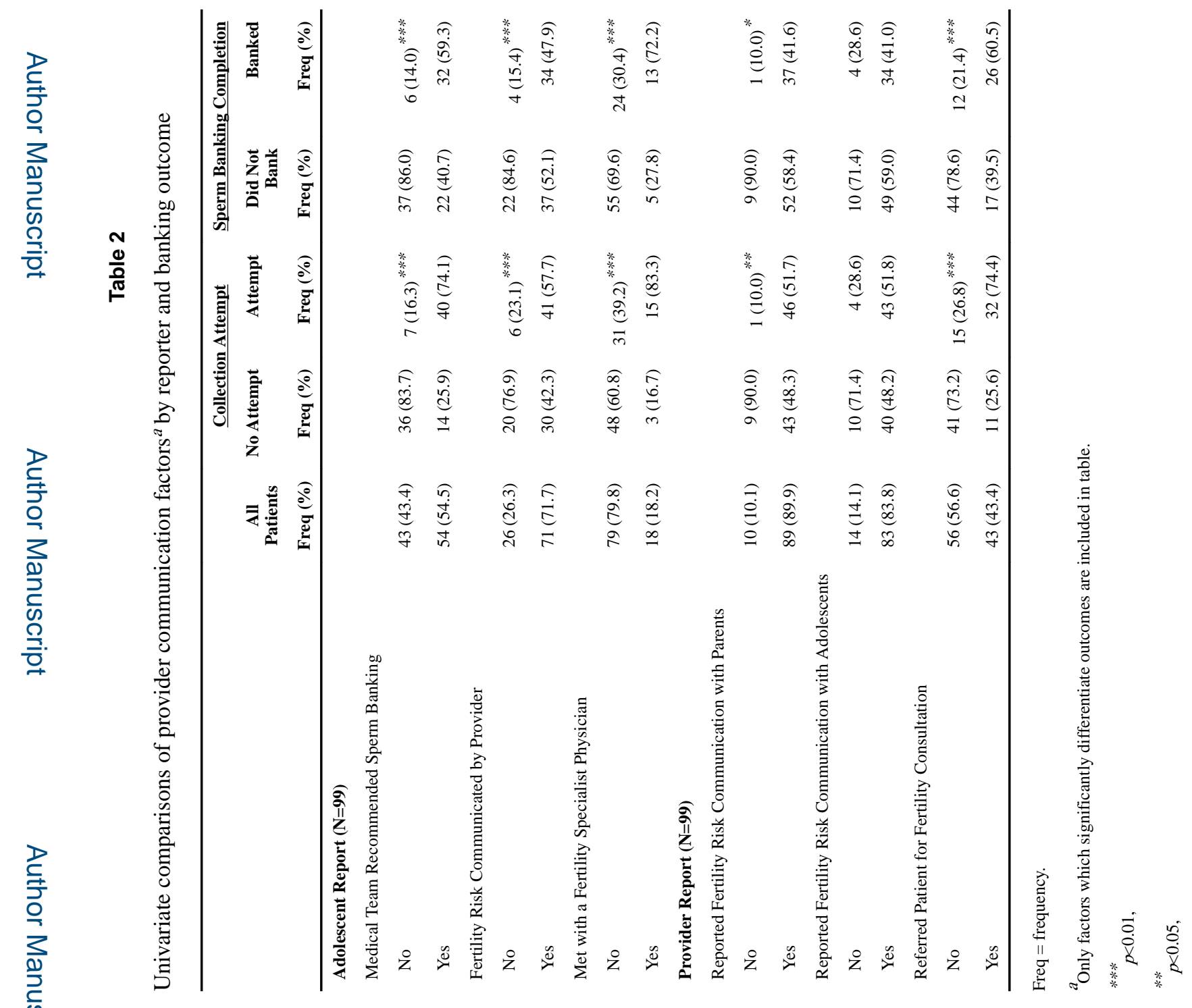




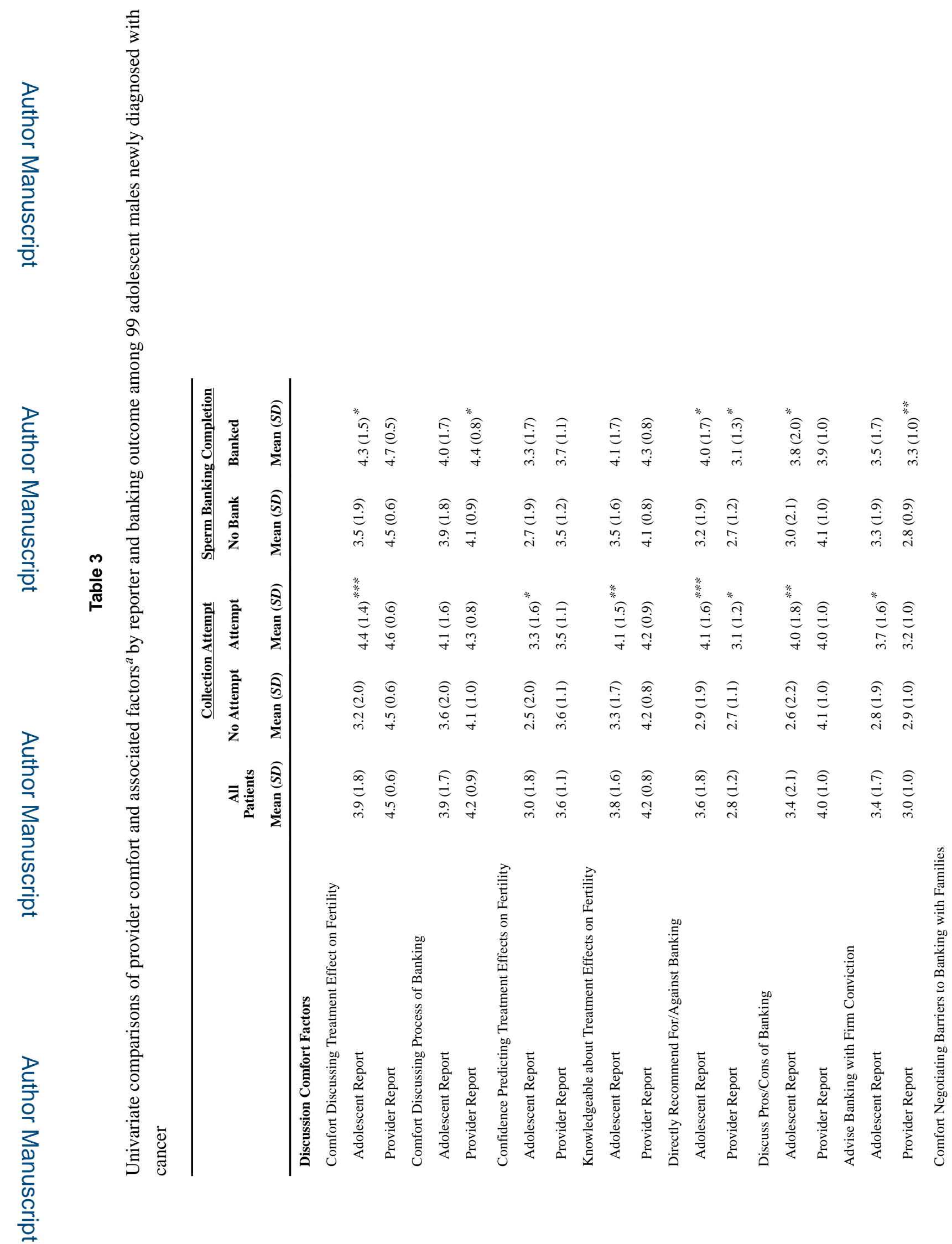

J Adolesc Health. Author manuscript; available in PMC 2018 March 01. 
Klosky et al.

Page 17

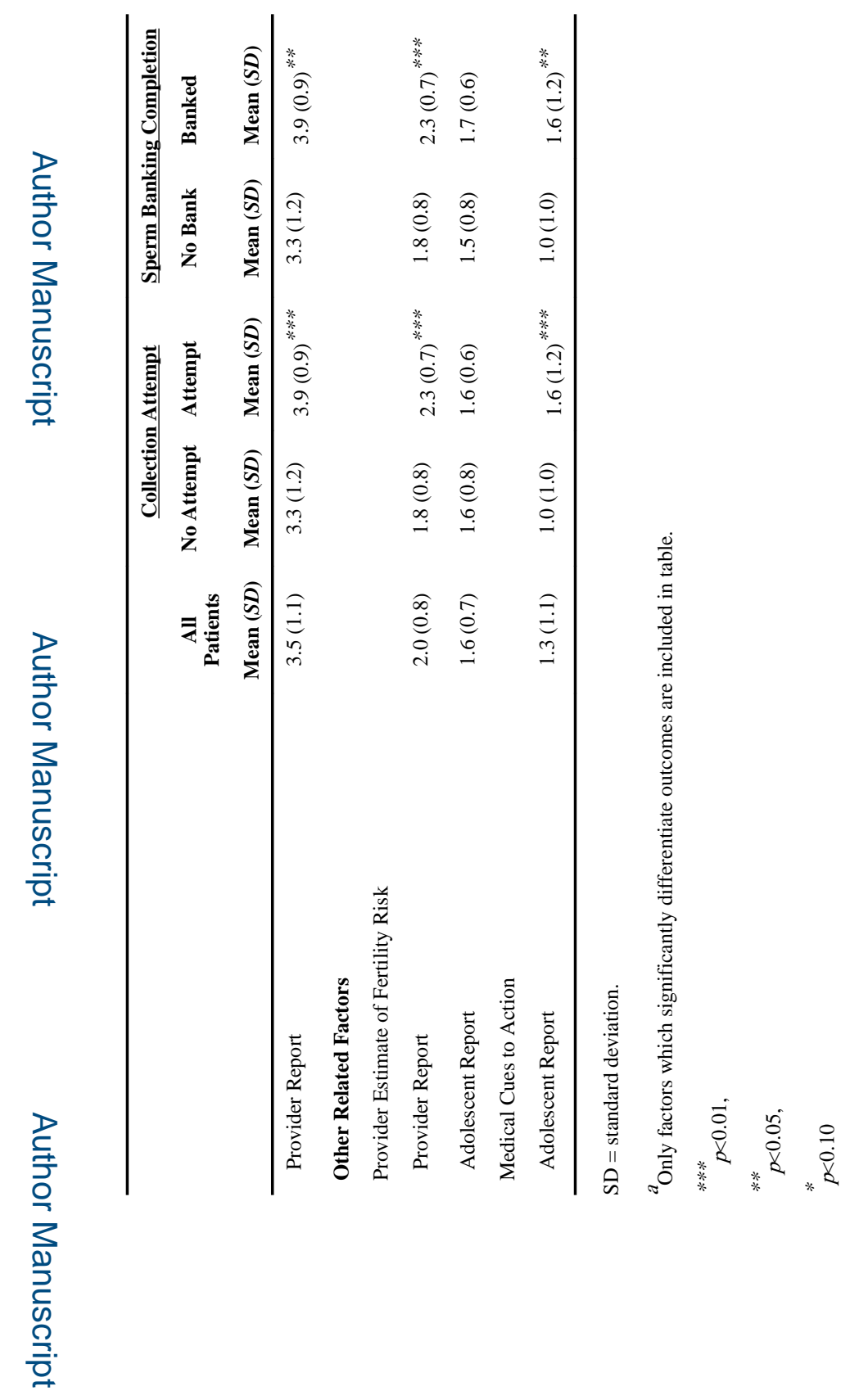

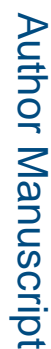

J Adolesc Health. Author manuscript; available in PMC 2018 March 01. 


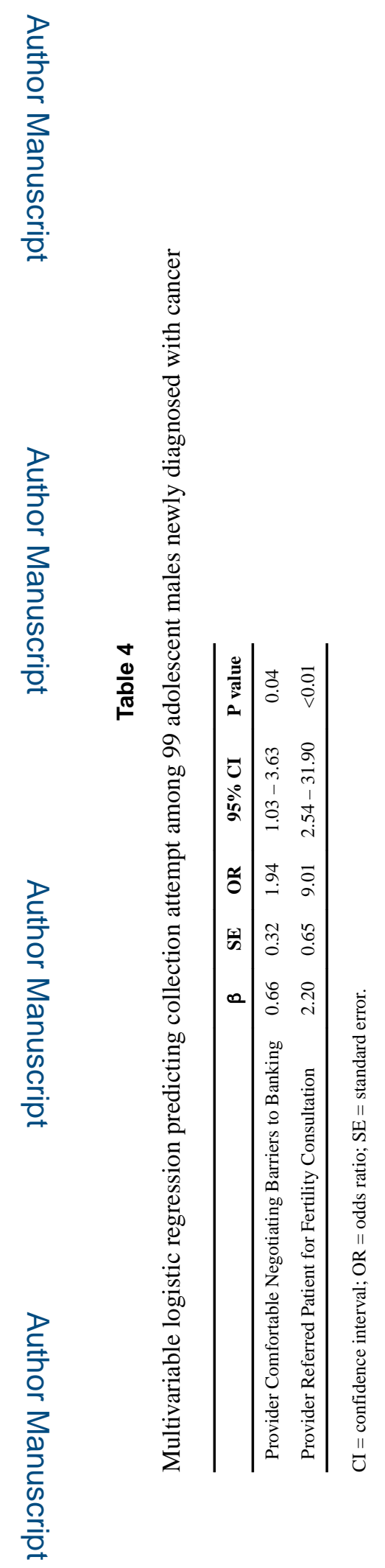




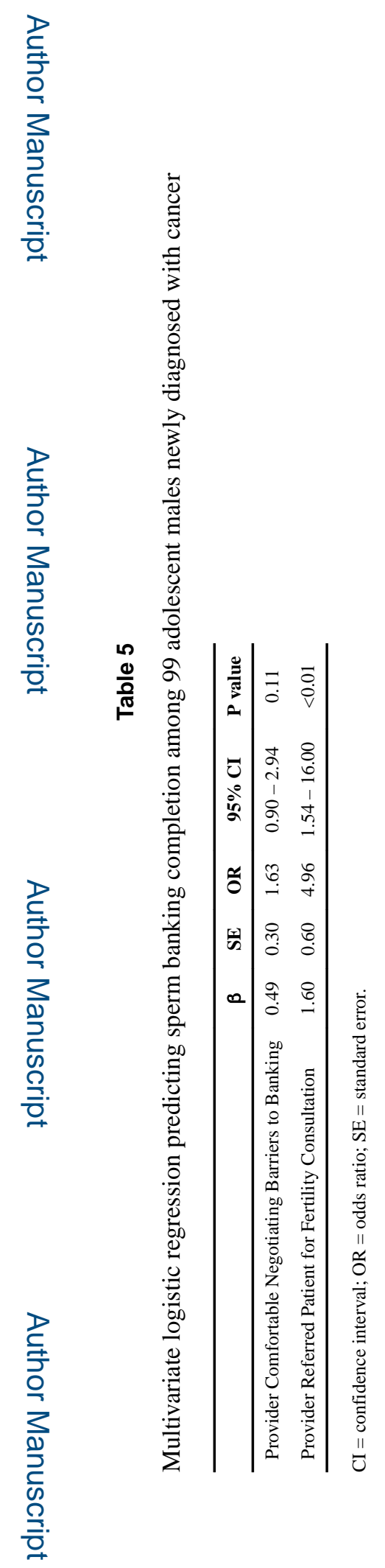

